\title{
THIẾT KẾ CẢI TIẾN KẾT CẤU ĐÀ̀U XE Ô TÔ KHÁCH GIƯỜNG NẰM NHẰM NÂNG CAO TÍNH AN TOÀN CON NGƯỜI TRONG VA CHẠM TRỰC DIỆN
}

\author{
NGUYỄN THÀNH TÂM ${ }^{1}$, NGUYẼ̃N CÔNG THÀNH ${ }^{2}$ \\ ${ }^{1}$ Trường Đại học Công nghiệp thành phố Hồ Chí Minh \\ ${ }^{2}$ Truờng Cao đẳng Kỹ thuật Cao thắng TP. Hồ Chí Minh; \\ nguyenthanhtam@iuh.edu.vn
}

Tóm tắt. Nghiên cứu này dựa vào tiêu chuẩn an toàn Châu Âu ECE R94, ECE R66, sử dụng phần mềm HYPERWORKS và MADYMO tiến hành xây dựng mô hình và mô phỏng phân tích tổn thương người lái và hành khách trong xe khách giường nằm xảy ra va chạm trực diện. Kết quả mô phỏng cho thấy, gia tốc va chạm cao làm cho con người bị tổn thương phần đầu rất nghiêm trọng. Nguyên nhân chủ yếu là do kết cấu đầu xe hấp thụ năng lượng ít. Trên cơ sở kết quả phân tích cơ chế tổn thương hành khách, tiến hành thiết kế kết cấu hấp thu năng lượng va chạm dựa trên sự thay đổi hình dạng và bề dày các thanh khung sát - xi đầu xe. Kết quả cải tiến cho thấy, các giá trị tổn thương của hành khách đã thỏa mãn yêu cầu của tiêu chuẩn Châu Âu ECE R94.

Từ khóa: xe khách giường nằm; va chạm trực diện; phân tích mô phỏng; hấp thụ năng lượng; tiêu chuẩn Châu Âu ECE R94

\section{IMPROVEMENT DESIGN OF SLEEPER COACHES FRONT STRUCTURE TO ENHANCE THE SAFETY OF HUMAN IN FRONTAL COLLISION}

\begin{abstract}
Based on ECE R94 and ECE R66 standard, the sleeper coaches safety simulation model was established and human injury was analysed in sleeper coaches frontal crash was analyed by HYPERWORKS and MADYMO software. The simulation results showed that the crash acceleration of sleeper coaches very high, the passenger's head was seriously injured. The main reasons were energy absorption of coaches head structure was very low. Based on the analysis results of injury mechanisms of passengers, the energy absorption structure of sleeper coaches front were improved. Improvement results showed that, the injury values of the passengers arcording to the requirements of European Standard ECE R94.
\end{abstract}

Key words. sleeper coaches, frontal collision, simulation analysis, energy absorption, ECE R94 standards

\section{LÒ̀I NÓI ĐẦU}

Theo Uỷ ban ATGT Quốc gia, trong 9 tháng đầu năm 2018, cả nước xảy ra 13.242 vụ tai nạn giao thông, làm chết 6.012 người, bị thương 10.319 người. [1]. Trong đó các vụ va chạm liên quan đến xe khách giường nằm có tính chất đặc biệt quan trọng làm nhiều người thương vong. Do đó, việc phân tích tổn thương của người lái và hành khách khi xe khách giường nằm xảy ra va chạm trực trở thành điểm nóng nghiên cứu.

Tác giả Nguyễn Thành Tâm đã ứng dụng phần mềm MADYMO phân tích tổn thương, cải tiến kết cấu đầu ô tô khách ghế ngồi để đảm bảo an toàn va chạm trực diện [2]. Tác giả Nguyễn Quang Anh nghiên cứu tính toán động lực học của ô tô và độ bền của khung xương khi ô tô xảy ra va chạm trực diện [3]. Tác giả Zhang Weigang nghiên cứu thiết kế cải tiến khung xương và sát-xi xe khách khi xảy ra va chạm trực diện bằng cách thiết kế bộ hấp thụ năng lượng loại ống thép, tuy nhiên sự va đập, gia tốc và ứng suất lớn dễ phá vỡ kết cấu sát-xi xe [4]. Liu C.K đã nghiên cứu mô phỏng quá trình va chạm của khung trước ô tô khi va chạm bằng phần mềm LS-DYNA và HYPERMESH [5]. Tác giả Muhammand Aamir Hassan đã nghiên cứu phân tích so sánh sự biến dạng kết cấu và thiệt hại về người ngồi trong xe trong các trường hợp xảy ra va chạm trực diện, mặt tường và cột, tuy nhiên không đề xuất hoặc cải tiến nhằm giảm tổn thương cho hành khách [6].

Nghiên cứu này ứng dụng kỹ thuật thiết kế mô hình bằng phần mềm SolidWorks, xây dựng mô hình phần tử hữu hạn bằng phần mềm HYPERMESH trong môi trường MADYMO tiến hành mô phỏng phân tích quá 
trình va chạm trực diện của ô tô khách giường nằm, đánh giá mức độ tổn thương hành khách thông qua các chỉ số đánh giá nguy hại các bộ phận trên cơ thể. Từ kết quả đó tiến hành cải tiến kết khung đầu xe hấp thụ năng lượng va chạm, hệ thống dây đai, túi khí theo phương pháp phù hợp với thực tiễn và tiết kiệm chi phí nhà sản xuất, đảm bảo an toàn cho người lái và hành khách thõa mãn yêu cầu tiêu chuẩn Châu Âu ECE R94.

\section{XÂY DỰNG MÔ HÌNH MÔ PHỎNG PHÂN TÍCH XE GIƯờnG NÀ̉M VA CHẠM TRỰC DIỆN}

Dựa vào mô hình $\mathrm{CAD} 3 \mathrm{D}$ xe khách giường nằm từ nhà sản xuất, sử dụng phần mềm HYPERMESH trong mô trường làm việc MADYMO tiến hành chia lưới và gán giá trị vật liệu khối lượng các bộ phận như động cơ, thùng nhiên liệu, hệ thống máy điều hòa không khí, cửa kính...Vật liệu được sử dụng cho kết cấu khung xương là sắt Q235, kết cấu khung sát-xi sàn xe là Q345 với các thuộc tính được thể hiện ở Bảng 1 [2].

Bảng 1: Thuộc tính vật liệu

\begin{tabular}{|c|c|c|c|c|}
\hline Tên & $\begin{array}{c}\text { Mô đun đàn hồi } \\
(\mathrm{GPa})\end{array}$ & Hệ số Poisson & $\begin{array}{c}\text { Khối lượng riêng } \\
\left(\mathrm{kg} / \mathrm{mm}^{3}\right)\end{array}$ & $\begin{array}{c}\text { Ứng suất giới hạn } \\
(\mathrm{MPa})\end{array}$ \\
\hline Q345 & 210 & 0,3 & $7,85.10^{-6}$ & 345 \\
\hline Q235 & 210 & 0,3 & $7,85.10^{-6}$ & 235 \\
\hline
\end{tabular}

Sau khi thiết lập được các thông số trên, tiến hành xuất tọa độ trọng tâm, khối lượng và moment quán tính cho từng thành phần khung xe để làm dữ liệu xây dựng trên MADYMO.

Từ các dữ liệu thu được tiến hành xây dựng mô hình đa thể cứng khung xe, trong đó phần khung đầu xe, dây đai an toàn, túi khí được xây dựng phần tử hữu hạn FE.MODEL nhằm phân tích biến dạng kết cấu, độ dày kết cấu khung sát-xi đầu xe là $8 \mathrm{~mm}$, độ dày khung xương đầu xe là $2 \mathrm{~mm}$; kết cấu thân giữa xe, thân cuối xe được sử dụng phần tử đa thể cứng SURFACE.ELLIPSOID, SURFACE.LANE; mặt đường, tường va chạm được sử dụng phần tử đa thể cứng SURFACE.ELLIPSOID. Vận tốc mô phỏng va chạm là $\mathrm{v}=13.9 \mathrm{~m} / \mathrm{s}$, gia tốc trọng trường là $\mathrm{g}=9.81 \mathrm{~m} / \mathrm{s} 2$ và hệ số ma sát giữa bánh xe và mặt đường là 0.2 . Nhằm trực quan phân tích biến dạng xe, thiết lập không gian an toàn cho xe theo tiêu chuẩn ECE R66. Để phân tích tổn thương con người, thiết lập người nộm Hybrid III 50th và các hệ thống an toàn (dây đai, túi khí) cho hành khách và người lái. Mô hình xe khách giường nằm đa thể cứng với đầu xe là phần tử hữu hạn sau khi xây dựng như ở Hình 1, vị trí khảo sát tổn thương người nộm Hybrid III 50th được thể hiện ở Hình 2.

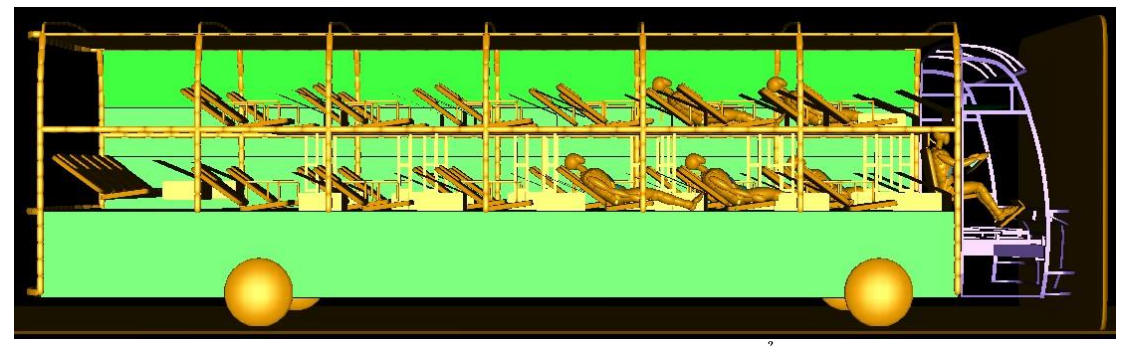

Hình 1: Mô hình mô phỏng phân tích tổn thương

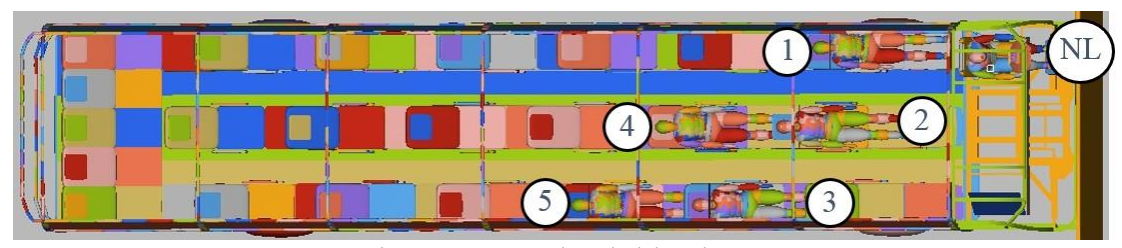

Hình 2: Vị trí khảo sát hành khách và người lái

\section{PHÂN TÍCH KẾT QUẢ MÔ PHỎNG}

Để mô phỏng phân tích một cách toàn diện quá trình va chạm và tổn thương hành khách và người lái khi xe xảy ra va chạm trực diện, nghiên cứu này ứng dụng tiêu chuẩn đánh giá tổn thương Châu Âu ECE R94, sử dụng người nộm Hybrid III 50th tiến hành mô phỏng phân tích tổn thương. Đánh giá tổn thương đầu của hành khách và người lái thông qua sử dụng phần mềm MADYMO PROTOCOL RATING và HYPERWIEW. Chỉ số tổn thương đầu (HIC) được tính toán qua công thức 1. 


$$
H I C=\max \left[\frac{1}{t_{2}-t_{1}} \int_{t_{1}}^{t_{2}} a(\mathrm{t}) \mathrm{dt}\right]^{2,5}\left(t_{2}-t_{1}\right)
$$

Trong đó:

$\mathrm{t}_{1}, \mathrm{t}_{2}$ : là hai thời điểm có sự thay đổi về giá trị gia tốc lớn nhất.

$\mathrm{t}_{2}-\mathrm{t}_{1}$ : là khoảng lấy lớn nhất $36 \mathrm{~ms}$.

a: là gia tốc theo thời gian tại tâm đầu người nộm.

\subsection{Hành khách trang bị dây đai 2 điểm, người lái 3 điểm (trường hợp 1)}

Trường hợp này, hành khách được trang bị dây đai 2 điểm, người lái được trang bị dây đai 3 điểm, giống như trang bị thực tế trên xe khách giường nằm hiện nay. Kết quả mô phỏng và giá trị tổn thương của hành khách và người lái được thể hiện ở Hình 3 và Bảng 2.

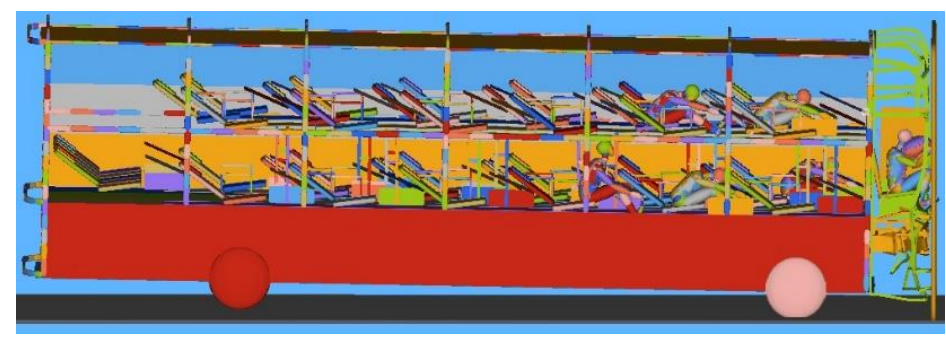

Hình 3: Kết quả mô phỏng cho trường hợp 1

Bảng 2 cho thấy, khi tài xế được trang bị dây đai 3 điểm và túi khí trước ngực, các chỉ số tổn thương đều vượt giá trị ngưỡng cho phép, đặc biệt là tổn của hành khách là do không trang bị dây đai ở vai. Do người lái được trang bị dây đai 3 điểm nên giá trị tổn thương thấp hơn so với tổn thương hành khách, tuy nhiên vẫn vượt ngưỡng an toàn cho phép.

Bảng 2: Giá trị tổn thương ở trường hợp 1

\begin{tabular}{|c|c|c|c|c|c|c|c|c|}
\hline & Chỉ số & $\begin{array}{l}\text { Tiêu } \\
\text { chuẩn }\end{array}$ & $\begin{array}{l}\text { Hành } \\
\text { khách } 1\end{array}$ & $\begin{array}{l}\text { Hành } \\
\text { Khách }\end{array}$ & $\begin{array}{l}\text { Hành } \\
\text { khách } 3\end{array}$ & $\begin{array}{l}\text { Hành } \\
\text { khách } 4\end{array}$ & $\begin{array}{l}\text { Hành } \\
\text { khách } 5\end{array}$ & Tài xế \\
\hline & HIC36 & 1000 & 7565 & 7668 & 6516 & 7932 & 5742 & 1139 \\
\hline ๑̂̀े & gia tốc đầu $(\mathrm{g})$ & 80 & 224.44 & 252.55 & 214.69 & 284.56 & 272.7 & 100.86 \\
\hline tau & $\begin{array}{c}\text { Vận tốc ép lồng ngực } \\
(\mathrm{m} / \mathrm{s})\end{array}$ & 1 & 0.15 & 0.16 & 0.20 & 0.24 & 0.36 & 0.26 \\
\hline
\end{tabular}

\subsection{Hành khách trang bị dây đai 3 điểm, người lái 3 điểm và túi khí (trường hợp 2)}

Trong trường hợp này, tiến hành sử dụng dây đai 3 điểm dành cho hành khách, tài xế được trang bị hệ thống an toàn theo quy định bao gồm dây đai an toàn và túi khí trước. Kết quả mô phỏng trong trường hợp này được thể hiện ở Hình 4 và Bảng 3 . Giá trị tổn thương ở Bảng 3 cho thấy, giá trị tổn thương đầu (HIC) của hành khách và người lái được đảm bảo, tuy nhiên giá trị gia tốc vẫn còn cao so với ngưỡng giá trị cho phép. Như vậy, cần thiết cải tiến kết cấu để tăng hấp thụ năng lượng va chạm, giảm gia tốc đầu của hành khách và người lái.

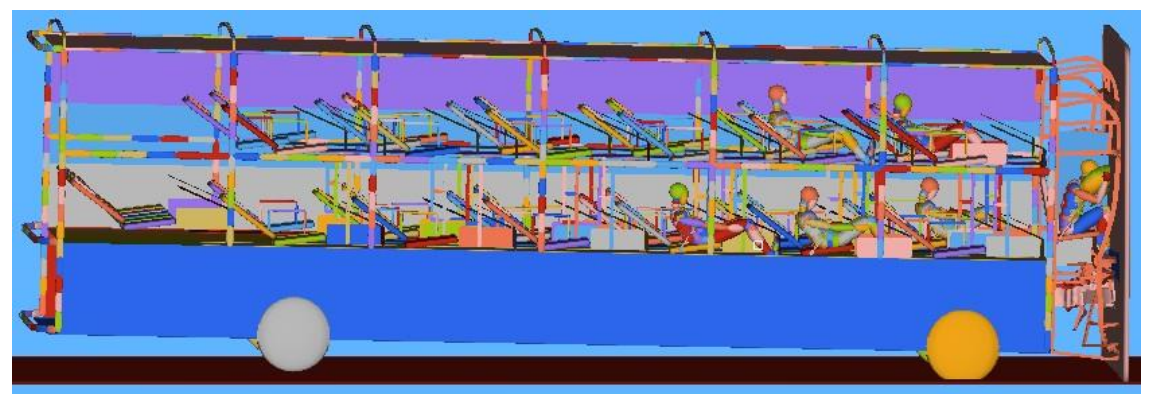

Hình 4: Kết quả mô phỏng cho trường hợp 2 

TÍNH AN TOÀN CON NGƯỜI TRONG VA CHẠM TRỬC DIỆN

Bảng 3: Giá trị tổn thương ở trường hợp 2

\begin{tabular}{|c|c|c|c|c|c|c|c|c|}
\hline \multicolumn{2}{|c|}{ Chỉ số } & $\begin{array}{c}\text { Tiêu } \\
\text { chuẩn }\end{array}$ & $\begin{array}{c}\text { Hành } \\
\text { khách 1 }\end{array}$ & $\begin{array}{c}\text { Hành } \\
\text { Khách } \\
2\end{array}$ & $\begin{array}{c}\text { Hành } \\
\text { khách 3 }\end{array}$ & $\begin{array}{c}\text { Hành } \\
\text { khách 4 }\end{array}$ & $\begin{array}{c}\text { Hành } \\
\text { khách 5 }\end{array}$ & Tài xế \\
\hline \multirow{3}{*}{ Đầu } & HIC36 & 1000 & 648 & 485 & 491 & 529 & 931 & 787 \\
\cline { 2 - 10 } & Gia tốc đầu (g) & 80 & 88.68 & 90.73 & 79.45 & 59.02 & 120.60 & 90.29 \\
\cline { 2 - 10 } & $\begin{array}{c}\text { Vận tốc ép lồng ngực } \\
(\mathrm{m} / \mathrm{s})\end{array}$ & 1 & 0.21 & 0.26 & 0.19 & 0.57 & 0.69 & 0.30 \\
\hline
\end{tabular}

\section{CẢI TIẾN GIẢM TỔN THƯƠNG}

Nhằm tăng tính năng an toàn cho hành khách và người lái khi xe xảy ra va chạm trực diện, nghiên cứu này ứng dụng cơ cấu hấp thu năng lượng va chạm để mô phỏng phân tích cơ chế tổn thương, kết cấu cơ khí hấp thụ năng lượng được thể hiện ở hình 5 . Thực hiện cải tiến kết cấu sát - xi ở giữa khung gầm trước xe theo dạng tròn lục giác, 2 thanh phía trước có bề dày $5 \mathrm{~mm}, 2$ thanh phía sau có bề dày $4 \mathrm{~mm}$. Kết cấu chưa cải tiến và cải tiến được thể hiện ở hình 5 .

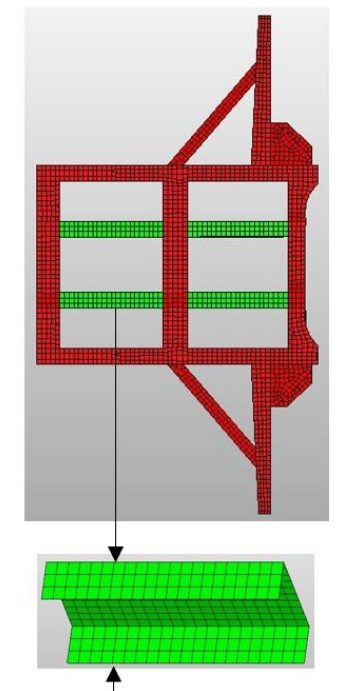

Kết cấu sát - xi chưa cải tiến

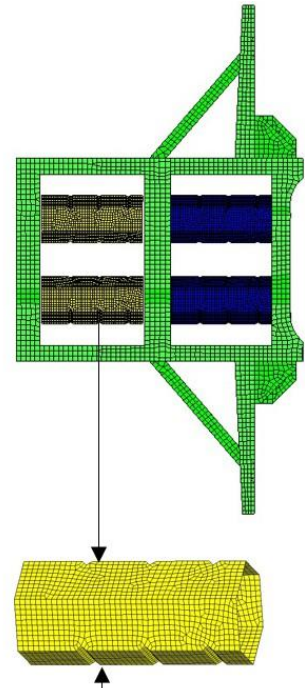

Kết cấu sát - xi cải tiến

Hình 5: Kết cấu sát - xi cải tiến

Cơ chế biến dạng kết cấu sau cải tiến được thể hiện ở Hình 6 , giá trị tổn thương đầu của hành khách và người lái được thể hiện ở Bảng 4 , Hình 7 . Bảng 4 và Hình 7 cho thấy, giá trị tổn thương đầu của hành khách và người lái sau cải tiến kết cấu đều giảm so với chưa cải tiến, thỏa mãn tiêu chuẩn an toàn Châu Âu ECE R94; giá trị gia tốc đầu của người lái giảm $50 \%$. Từ kết quả này cho thấy, kết cấu sát xi được cải tiến hấp thụ năng lượng va chạm rất tốt.

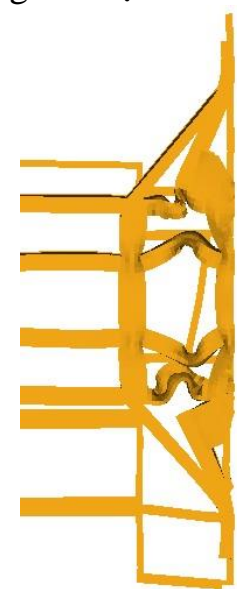

(a): Trước cải tiến

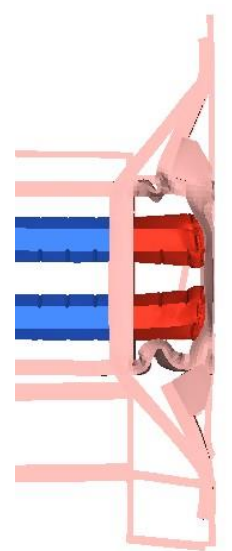

(b): Sau cải tiến

Hình 6: So sánh kết cấu biến dạng trước và sau cải tiến 
Bảng 4. Giá trị tổn thương trường hợp cải tiến kết cấu sát - xi đầu xe cho trường hợp 2.

\begin{tabular}{|c|c|c|c|c|c|c|c|c|}
\hline \multicolumn{2}{|c|}{ Chỉ số } & $\begin{array}{c}\text { Tiêu } \\
\text { chuẩn }\end{array}$ & $\begin{array}{c}\text { Hành } \\
\text { khách 1 }\end{array}$ & $\begin{array}{c}\text { Hành } \\
\text { Khách 2 }\end{array}$ & $\begin{array}{c}\text { Hành } \\
\text { khách 3 }\end{array}$ & $\begin{array}{c}\text { Hành } \\
\text { khách 4 }\end{array}$ & $\begin{array}{c}\text { Hành } \\
\text { khách 5 }\end{array}$ & Tài xế \\
\hline \multirow{3}{*}{ Đầu } & HIC36 & 1000 & 669 & 476 & 533 & 518 & 661 & 289 \\
\cline { 2 - 34 } & gia tốc đầu $(\mathrm{g})$ & 80 & 61.02 & 53.63 & 55.44 & 56.08 & 70.76 & 45.05 \\
\cline { 2 - 8 } & Vận tốc ép lồng ngực $(\mathrm{m} / \mathrm{s})$ & 1 & 0.30 & 0.34 & 0.33 & 1.16 & 0.24 & 0.20 \\
\hline
\end{tabular}

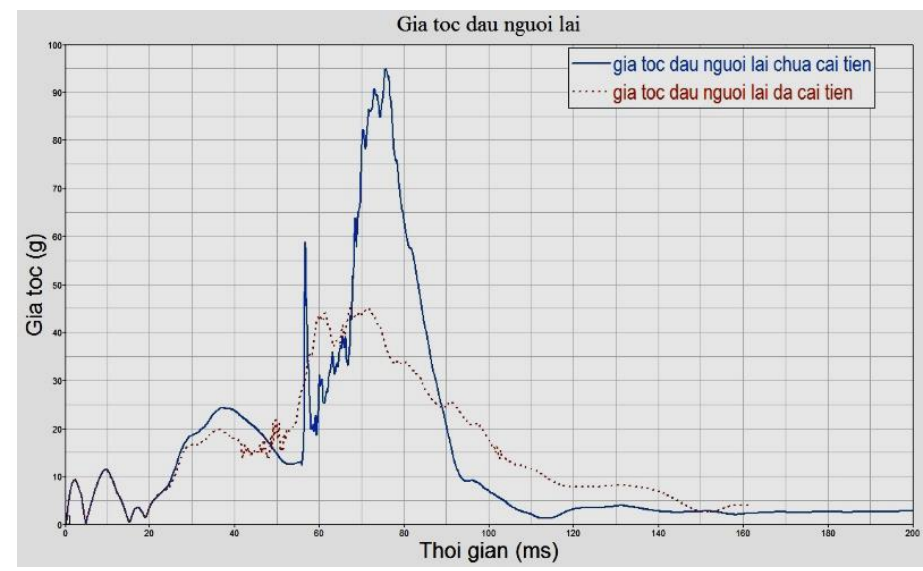

\section{KẾT LUẬN}

Hình 7. Biểu đồ so sánh gia tốc đầu người lái trước và sau cải tiến.

Nghiên cứu này dựa vào tiêu chuẩn an toàn Châu Âu ECE R94, ứng dụng phần mềm HYPERMESH và MADYMO đã tiến hành nghiên cứu an toàn tổn thương hành khách nằm và người lái trong xe khách khi xảy ra va chạm trực diện. Kết quả mô phỏng phân tích cho thấy, mặc dù hành khách và người lái có trang bị hệ thống an toàn (dây đai, túi khí) nhưng giá trị tổn thương đầu lớn hơn giá trị tiêu chuẩn. Điều này cho thấy, kết cấu xe hấp thụ ít năng lượng va chạm. Để giảm tổn thương và an toàn cho hành khách và người lái, cần thiết kế bộ hấp thụ năng lượng đặt trước đầu xe. Khi đó giá trị tổn thương đầu của hành khách và người lái trong trường hợp 2 thỏa mãn tiêu chuẩn ECE R94.

\section{REFERENCES}

[1] Nguyễn Vương. Hơn 6.000 người chết vì tai nạn giao thông trong 9 tháng đầu năm: https://vov.vn/xa-hoi/hon6000-nguoi-chet-vi-tai-nan-giao-thong-trong-9-thang-dau-nam-820040.vov.

[2] Nguyễn Thành Tâm. Nghiên cứu nâng cao tính an toàn con người trong ô tô khách xảy ra va chạm trực diện, Khoa học và Công nghệ, số 25. 2017.

[3] Nguyễn Quang Anh, Nghiên cứu động lực học và độ bền của khung vỏ ô tô khi va chạm trực diện, Học Viện Kỹ Thuật Quân Sự, Hà Nội, 2007.

[4] Zhang Weigang, Simulation of bus safety body structure, Hunan University, China, 2006.

[5] Liu, C.K., Song, X.P. and Wang, J. (2014), Simulation Analysis of Car Front Collision Based on LS-DYNA and Hyper Works. Journal of Transportation Technologies, 4, 337-342.

[6] Muhammad Aamir Hassan, Comparison of structural damage and occupant injuries corresponding to a vehicle collision onto a pole versus a flat barrier, Bachelor of Engineering, N.E.D. University of Engineering and technology Karachi, Pakistan, 2002.

Ngày nhận bài: 01/03/2019 Ngày chấp nhận đăng: 30/05/2019 